\title{
Epidermal growth factor receptor (EGFR) mutations in lung cancer: preclinical and clinical data
}

\author{
S.E.D.C. Jorge, S.S. Kobayashi and D.B. Costa \\ Division of Hematology/Oncology, Department of Medicine, Beth Israel Deaconess Medical Center, \\ Harvard Medical School, Boston, MA, USA
}

\begin{abstract}
Lung cancer leads cancer-related mortality worldwide. Non-small-cell lung cancer (NSCLC), the most prevalent subtype of this recalcitrant cancer, is usually diagnosed at advanced stages, and available systemic therapies are mostly palliative. The probing of the NSCLC kinome has identified numerous nonoverlapping driver genomic events, including epidermal growth factor receptor (EGFR) gene mutations. This review provides a synopsis of preclinical and clinical data on EGFR mutated NSCLC and EGFR tyrosine kinase inhibitors (TKIs). Classic somatic EGFR kinase domain mutations (such as L858R and exon 19 deletions) make tumors addicted to their signaling cascades and generate a therapeutic window for the use of ATP-mimetic EGFR TKIs. The latter inhibit these kinases and their downstream effectors, and induce apoptosis in preclinical models. The aforementioned EGFR mutations are stout predictors of response and augmentation of progression-free survival when gefitinib, erlotinib, and afatinib are used for patients with advanced NSCLC. The benefits associated with these EGFR TKIS are limited by the mechanisms of tumor resistance, such as the gatekeeper EGFR-T790M mutation, and bypass activation of signaling cascades. Ongoing preclinical efforts for treating resistance have started to translate into patient care (including clinical trials of the covalent EGFR-T790M TKIs AZD9291 and CO-1686) and hold promise to further boost the median survival of patients with EGFR mutated NSCLC.
\end{abstract}

Key words: Mutation; Lung cancer; Non-small-cell lung cancer; EGFR; EGFR inhibitor; Precision therapies; Resistance

\section{Lung cancer and driver oncogenes}

Lung cancer is composed of non-small-cell lung cancers (NSCLCs; which account for over $85 \%$ of diagnosed cases), small-cell lung cancers, and neuroendocrine tumors; and this group of malignancies leads cancer-related mortality for both men and women worldwide (1). In the United States alone, in 2014, the number of new cases of lung cancer is projected to be 224,210 and the number of deaths 159,260 (2), with this recalcitrant cancer alone accounting for a quarter of all causes of cancer deaths (2). Worldwide, the number of new cases exceeds a million per year (1). The single most important risk factor for developing lung cancer is a personal history of cigarette smoking, and genome-wide association studies (GWAS) of patients with lung cancer have provided strong evidence for a tobacco-dependent susceptibility region in chromosome 15q25.1, containing genes (CHRNA3, CHRNA5, and CHRNB4) that encode for nicotinic acetylcholine receptors $(3,4)$. However, up to $20 \%$ of lung cancers in the United States occur in never-smokers, defined as persons who have smoked fewer than 100 cigarettes in their lifetime (5). NSCLCs in never-smokers account for the seventh most frequent cause of cancer mortality worldwide (6). The risk factors, both environmental and inherited, for lung cancer in never-smokers are poorly understood, and GWAS have been relatively unrevealing of a unifying genetic basis $(5,7)$. As early as a decade ago, the only available palliative options for advanced NSCLCs included platinum-doublet cytotoxic chemotherapies, and evidence-based treatment guidelines combined all types of NSCLC into one single entity (8).

The last decade has uncovered knowledge on the molecular determinants of lung cancer, and the probing of the NSCLC kinome using next-generation sequencing techniques has identified numerous nonoverlapping driver genomic events (i.e., activating mutations or rearrangements) involving targetable kinases, including epidermal growth factor receptor (EGFR), anaplastic lymphoma kinase (ALK), v-Raf murine sarcoma viral oncogene homolog B1, V-erb-b2 erythroblastic leukemia viral oncogene homolog 2 (ERBB2), rearranged during transfection, c-ros oncogene 1 , and neurotrophic tyrosine kinase receptor type 1, among others. Notwithstanding the gaps in knowledge of why NSCLCs develop in never-smokers, it is now well

Correspondence: D.B. Costa and/or S.S. Kobayashi, Division of Hematology/Oncology, Beth Israel Deaconess Medical Center, 330 Brookline Av., Boston, MA 02215, USA. Fax: +617-975-5665. E-mail: dbcosta@bidmc.harvard.edu and/or skobayas@bidmc.harvard.edu

Received May 8, 2014. Accepted July 7, 2014. First published online September 5, 2014. 
established that never-smoker-related NSCLCs comprise diseases with a distinct biology - compared to smokingrelated NSCLCs (where undruggable v-ki-ras2 Kirsten rat sarcoma viral oncogene homolog mutations are more frequent) - marked by an increased incidence of targetable mutations in oncogenes (Figure 1). The near-universal prevalence of driver oncogenes in lung adenocarcinomas from never-smokers truly makes these diseases putative oncogene-driven malignancies, in which the use of kinase inhibitors should be prioritized. The evolving division of NSCLCs into distinct actionable subtypes with mutually exclusive driver oncogenes has helped usher the development of small molecule tyrosine kinase inhibitors (TKIs) that are now either clinically available or in early to late stage development as palliative therapies in advanced NSCLC (9-12).

This review focuses on EGFR mutated NSCLC and provides an overview of the preclinical and clinical data associated with the use of kinase inhibitors in this cohort of lung cancers. The contents of this review were originally presented at the São Paulo School of Advanced Science meeting entitled "Oncogenesis and Translational Medicine for Cancer Treatment" (February 2014, Ribeirão Preto, SP, Brazil) and expands topics covered in a recent review on driver oncogenes in NSCLC (13).

\section{EGFR}

EGFR (alternatively named ErbB1 or HER1) is part of the ErbB family of transmembrane receptor tyrosine kinases involved in signal transduction pathways that regulate proliferation and apoptosis (14). ErbB members exist as monomers that dimerize in response to receptor-specific ligands, such as amphiregulin and epidermal growth factor (EGF), for EGFR. EGFR has an equilibrium that dictates its ability to transition into inactive and active states $(15,16)$, with the latter allowing the transfer of a phosphate from adenosine triphosphate (ATP) to a peptide substrate that subsequently engages downstream signaling effectors through downstream prosurvival and antiapoptotic targets $(14,15)$. The active ATP binding site of EGFR lies in the cleft between the $\mathrm{N}$-terminal and $\mathrm{C}$-terminal lobes, within its kinase domain $(15,16)$.

\section{EGFR mutations in NSCLC}

EGFR mutations were initially reported in 2004 and currently define the most prevalent actionable genomically classified subgroup of NSCLC (17-19). EGFR mutations, pertinent to NSCLC, are spatially located within the ATP binding site of the kinase (Figure 2A). The most frequent EGFR mutations (Figure 2B) commonly termed classic or sensitizing activating mutations - are in-frame deletions (around amino acid residues 747 to 750 ) of exon 19 (45\% of EGFR mutations) and the exon 21 L858R mutation (40\% of EGFR mutations) (20). The third most frequent class of EGFR mutations is composed of in-frame insertions within exon 20 (5-10\% of EGFR mutations) of the kinase $(21,22)$. Other recurrent mutations include exon 18 point mutations in position G719 (3\% of EGFR mutations), the exon 21 L861Q mutation (2\% of EGFR mutations), and in-frame exon 19 insertions ( $<1 \%$ of EGFR mutations) $(20,23)$. EGFR mutations are more frequent in tumors with adenocarcinoma histology, in never-smokers or light smokers, in women with NSCLC, and in patients with East Asian
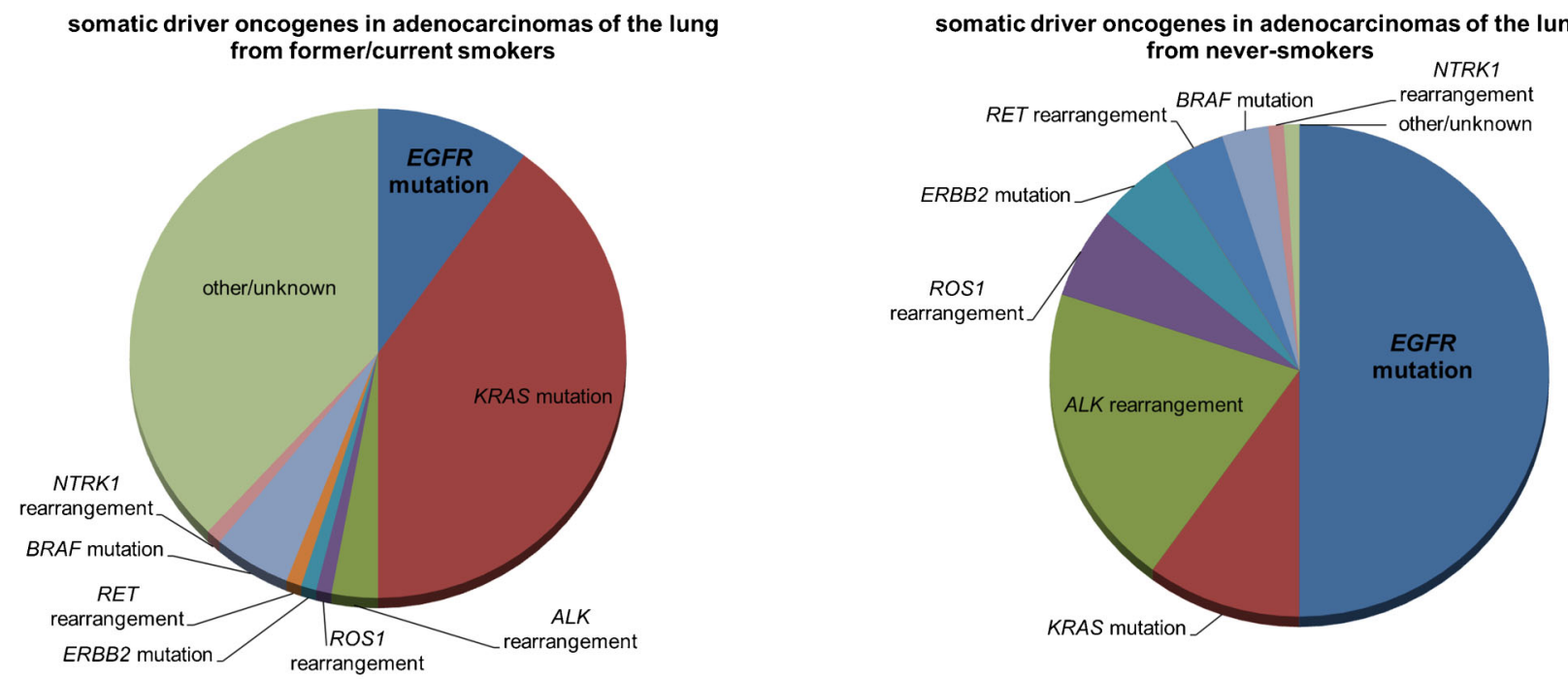

Figure 1. Pie chart of the frequency of driver oncogene mutations in lung adenocarcinomas from former/current smokers (left panel) and from never-smokers (right panel). Note the striking difference between the higher frequency of EGFR, ALK, ROS1, ERBB2, RET, BRAF (V600E), and NTRK1 mutations in never-smokers, and the higher frequency of KRAS mutations in smokers. 


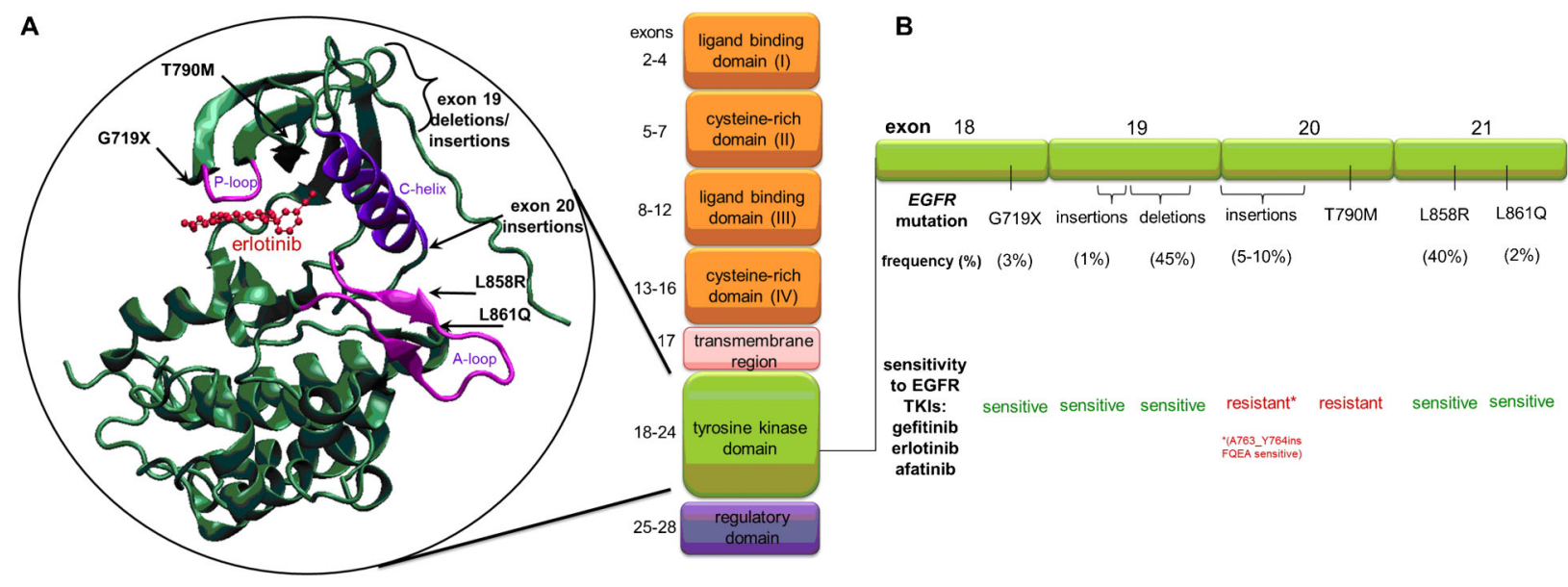

Figure 2. Epidermal growth factor receptor (EGFR) mutations in non-small-cell lung cancer (NSCLC). $A$, Structure of the kinase domain of EGFR in complex with erlotinib (based on Protein Data Bank [PDB] accession code 1M17) and location of the most common EGFR mutations. B, Frequency, exon location, and sensitivity to EGFR inhibitors of the most common EGFR mutations. TKIs: tyrosine kinase inhibitors.

ethnicities (20). Approximately $15 \%$ of all NSCLCs in patients with European or African ethnicities, 35\% of NSCLCs in East Asians, and $50 \%$ of NSCLCs in neversmokers are EGFR mutation positive. The paucity of classic EGFR mutations in tumors with squamous cell carcinomas of the lung has led to the widespread recommendation of obtaining the genotype (usually either complete or allele-specific sequencing of key regions of exons 18 to 21 of EGFR) only in nonsquamous NSCLCs, except in cases with mixed histologies or with high clinical suspicion (i.e., never-smokers). The College of American Pathologists, International Association for the Study of Lung Cancer, and Association for Molecular Pathology recommend rapid testing for EGFR mutations and $A L K$ rearrangements in all patients with advanced-stage adenocarcinoma (24). The etiology (environmental or inherited) that underlies the initial genomic insult that either leads to or selects for EGFR mutations in lung tissues remains elusive. Interestingly, rare inherited germline EGFR mutations (such as T790M and V843I) can be genomic loci associated with an increased familial clustering of EGFR mutated NSCLC, in which tumors develop when a somatic classic EGFR mutation associates with the inherited allele $(5,25)$.

\section{Structural and biochemical characterization of EGFR mutants in lung cancer}

The crystal structures and enzymatic assays of some EGFR mutations (such as L858R, G719S, T790M, and D770_N771insNPG) have elucidated the mechanism of activation and response to kinase inhibitors of these mutants (16). As an example, EGFR-L858R shifts the kinase equilibrium toward the active state $(15,16,26)$, with the mutated EGFR enhancing its homodimerization and association with wild-type (WT) EGFR (27). In kinetic models of L858R - and also exon 19 deletion EGFR mutated proteins - one notes a decreased affinity for ATP and enhanced affinity for EGFR TKIs compared to the WT receptor (16). Hence, these mutations generate a wide therapeutic window for EGFR TKIs in relation to WT EGFR (16). In preclinical models, nanomolar concentrations (i.e., concentrations that are 100 to 1000 times lower than achievable serum concentrations) of gefitinib, erlotinib, and afatinib are able to effectively inhibit classic EGFR mutants while sparing the WT receptor (16). The aforementioned change in affinity for ATP is one of the hallmarks of oncogene kinase mutants that respond to TKIs, and the EGFR TKI-resistant EGFR-T790M mutation (as discussed later) is thought to increase EGFR affinity for ATP as a mechanism of reducing the effectiveness of inhibition by gefitinib or erlotinib $(16,28)$. In contrast to models for EGFR-L858R and exon 19 deletions/insertions, the crystal structure and enzymatic assays for the prototypical EGFR exon 20 insertion D770_N771insNPG disclosed that this insertion locks the kinase's C-helix in its active position but with an EGFR TKI binding mode and apparent affinity similar to that of WT EGFR (22). The latter explains why the most prevalent EGFR exon 20 insertion mutations do not sensitize to available EGFR TKIs. The atypical EGFR exon 20 insertion mutation A763_Y764insFQEA possesses kinetics/structure that more closely resembles EGFR-L858R and is therefore an EGFR TKI-sensitizing mutation (22).

EGFR mutations, by favoring the active kinase state, are oncogenic in NSCLC cell lines, mouse models, and human tumors. They do this by inducing EGFR-mediated antiapoptotic and prosurvival proteins via downstream 
targets of the mitogen-activated protein kinase/ extracellular-signal-regulated kinase, janus kinase/signal transducer and activator of transcription, and phosphatidylinositol-3-kinase/protein kinase B cascades (14). These signaling networks make cells with EGFR mutations dependent on this ErbB member for their survival (Figure 3A). EGFR mutant inhibition leads to upregulation and activation of proapoptotic molecules that initiate the intrinsic mitochondrial apoptotic pathway by affecting the balance of pro- vs antiapoptotic BCL-2 family members. The most well-described apoptotic signal induced by EGFR inhibition is that of the $\mathrm{BH} 3$ domain-only molecule BIM (Figure $3 \mathrm{~A}$ ), which in the mitochondria binds to antiapoptotic BCL-2 members and antagonizes their antiapoptotic activity (29). Therefore, the apoptotic response induced by EGFR TKIs defines an oncogeneaddicted model.

\section{Clinical data on EGFR TKIs for EGFR mutated NSCLC and approval of gefitinib, erlotinib, and afatinib}

Gefitinib and erlotinib, oral reversible EGFR TKIs, were approved for the treatment of unselected NSCLC prior to the information on EGFR mutations as predictive biomarkers for EGFR TKIs $(30,31)$. Both erlotinib and gefitinib were also tested in combination with platinum-based chemotherapies, and no improvement in response or survival was demonstrated $(30,31)$. The limited activity of these TKIs in non-EGFR genotyped, or unselected, NSCLCs, is mostly clear when EGFR mutation status is obtained. The response rate (RR) of EGFR WT tumors (many harboring other driver oncogene alterations) is below $2 \%$ with $250 \mathrm{mg}$ daily gefitinib (10), and in randomized trials that restrict enrollment to EGFR WTbearing NSCLCs, the traditional cytotoxic single agent docetaxel produces superior $\mathrm{RR}$, progression-free survival (PFS), and overall survival (OS) than $150 \mathrm{mg}$ daily erlotinib (32). Therefore, the use of EGFR TKIs in tumors without an EGFR sensitizing mutation leads to minimal clinical benefits in most cases and has fallen out of favor.

EGFR TKIs (gefitinib, erlotinib, and afatinib) lead to responses in most patients with advanced NSCLCs harboring sensitizing EGFR activating mutations when given as first or further lines of treatment. In the late 2000s and early 2010s, randomized studies confirmed the predictive value of classic EGFR mutations as the major biomarkers for the beneficial effects of gefitinib $(10,33)$, erlotinib (11), and afatinib (12). It is important to note that the most predominant somatic mutations that were included in these trials were EGFR exon 19 deletions (the most common is delE746_A750) and L858R; therefore, all current genomic-based approvals for EGFR TKIs are limited to tumors with the aforementioned classic

A

Activation of classic EGFR mutants and inhibition by EGFR TKIs

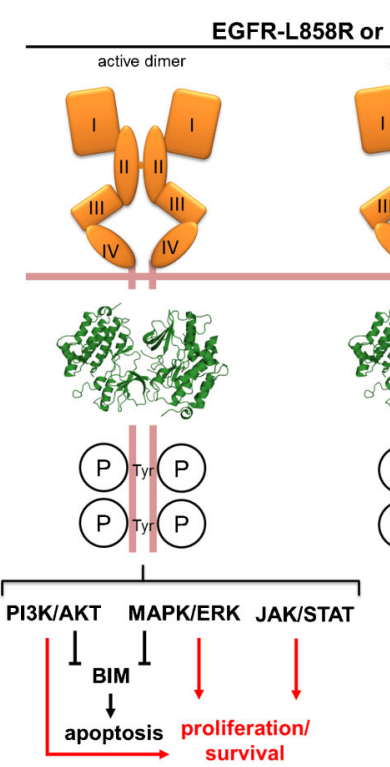
FF-delE746_A750 active dimer

EGFR TKI action

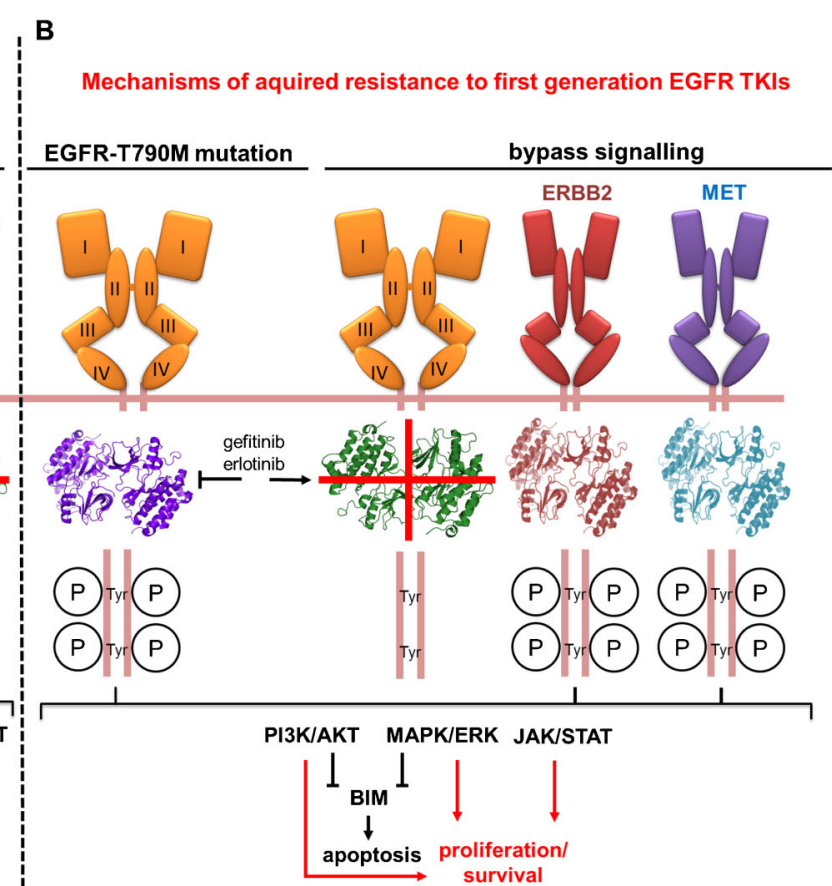

Mechanisms of aquired resistance to first generation EGFR TKIs

Figure 3. A, Mechanism of activation of the JAK/STAT, MAPK/ERK and PI3K/AKT pathways by epidermal growth factor receptor (EGFR) mutations and their inhibition by EGFR tyrosine kinase inhibitors (TKIs). B, Mechanisms of acquired resistance to EGFR TKIs in EGFR mutated non-small-cell lung cancer (NSCLC) with emphasis on the EGFR-T790M resistant mutation and oncogene bypass tracks that re-activate downstream signaling cascades. 
Table 1. Clinical trials of gefitinib, erlotinib and afatinib against platinum-doublet chemotherapy as first line therapy for advanced $E G F R$ mutated NSCLC.

\begin{tabular}{|c|c|c|c|c|c|c|c|c|c|}
\hline \multirow{2}{*}{$\begin{array}{l}\text { Trial (reference) } \\
\text { [no. patients/drug] }\end{array}$} & \multicolumn{3}{|c|}{ RR (RECIST) } & \multicolumn{3}{|c|}{ PFS (months) } & \multicolumn{3}{|c|}{ OS (months) } \\
\hline & $\begin{array}{c}\text { EGFR } \\
\text { TKI }\end{array}$ & $\begin{array}{l}\text { Platinum- } \\
\text { doublet }\end{array}$ & $\mathrm{P}$ & $\begin{array}{l}\text { EGFR } \\
\text { TKI }\end{array}$ & $\begin{array}{l}\text { Platinum- } \\
\text { doublet }\end{array}$ & $\mathrm{HR}(\mathrm{P})$ & $\begin{array}{l}\text { EGFR } \\
\text { TKI }\end{array}$ & $\begin{array}{l}\text { Platinum- } \\
\text { doublet }\end{array}$ & $\mathrm{HR}(\mathrm{P})$ \\
\hline $\begin{array}{l}\text { IPASS }(10,33) \\
\text { [437/gefitinib] }\end{array}$ & $71.2 \%$ & $47.3 \%$ & $<0.001$ & 9.5 & 6.3 & $\begin{array}{c}0.48 \\
(<0.001)\end{array}$ & 21.6 & 21.9 & $\begin{array}{c}1 \\
(0.99)\end{array}$ \\
\hline $\begin{array}{l}\text { NEJ002 (37) } \\
\text { [230/gefitinib] }\end{array}$ & $73.7 \%$ & $30.7 \%$ & $<0.001$ & 10.8 & 5.4 & $\begin{array}{c}0.30 \\
(<0.001)\end{array}$ & 30.5 & 23.6 & $\begin{array}{c}\text { NR } \\
(0.31)\end{array}$ \\
\hline $\begin{array}{l}\text { WJTOG } 3405 \text { (36) } \\
\text { [177/gefitinib] }\end{array}$ & $62.1 \%$ & $32.2 \%$ & $<0.001$ & 9.2 & 6.3 & $\begin{array}{c}0.49 \\
(<0.001)\end{array}$ & 30.9 & $\begin{array}{c}\text { not } \\
\text { reached }\end{array}$ & $\begin{array}{c}1.64 \\
(0.21)\end{array}$ \\
\hline $\begin{array}{l}\text { OPTIMAL (38) } \\
\text { [154/erlotinib] }\end{array}$ & $83 \%$ & $36 \%$ & $<0.001$ & 13.1 & 4.6 & $\begin{array}{c}0.16 \\
(<0.001)\end{array}$ & 22.6 & 28.8 & $\begin{array}{l}1.06 \\
(0.68)\end{array}$ \\
\hline $\begin{array}{l}\text { EURTAC (11) } \\
\text { [173/erlotinib] }\end{array}$ & $58 \%$ & $15 \%$ & $<0.001$ & 9.7 & 5.2 & $\begin{array}{c}0.37 \\
(<0.001)\end{array}$ & 19.3 & 19.5 & $\begin{array}{c}1.04 \\
(0.87)\end{array}$ \\
\hline $\begin{array}{l}\text { LUX-Lung } 3(12) \\
\text { [345/afatinib] }\end{array}$ & $56 \%$ & $23 \%$ & 0.001 & 11.1 & 6.9 & $\begin{array}{c}0.58 \\
(<0.001)\end{array}$ & NR & NR & $\begin{array}{c}1.12 \\
(0.60)\end{array}$ \\
\hline $\begin{array}{l}\text { LUX-Lung } 6 \text { (39) } \\
\text { [366/afatinib] }\end{array}$ & $66.9 \%$ & $23 \%$ & $<0.001$ & 11 & 5.6 & $\begin{array}{c}0.28 \\
(<0.001)\end{array}$ & 22.1 & 22.2 & $\begin{array}{c}0.95 \\
(0.76)\end{array}$ \\
\hline
\end{tabular}

EGFR: epidermal growth factor receptor; TKI: tyrosine kinase inhibitor; NSCLC: non-small-cell lung cancer; RR: response rate; PFS: progression-free survival; OS: overall survival; RECIST: response evaluation criteria in solid tumors; ref: reference, HR: hazard ratio; NR: not reported. Differences in RR were calculated by each publication using Fisher's exact test. The HR was calculated by each publication using Cox regression analysis and differences in PFS compared using the log-rank test.

mutations. The authors are aware of at least eight randomized phase III trials that specifically compared an EGFR TKI against systemic platinum-based chemotherapies in the first-line setting of advanced NSCLC (34). These include IPASS (10), First-SIGNAL (35), WJTOG 3405 (36), NEJ002 (37), OPTIMAL (38), EURTAC (11), Lux-LUNG 3 (12), and Lux-LUNG 6 (39). Table 1 shows PFS, RR, and OS for these trials. In all trials, the RR with the EGFR TKI was nearly double (if not more) that of a diverse array of platinum-doublets and the PFS times were significantly longer (in most trials it exceed a median of 9 months for the EGFR TKI). It is interesting to note that most of these trials were not designed to, and did not, demonstrate an improvement in survival with the initial use of an EGFR TKI compared to cytotoxic chemotherapy, data that can be explained by the very high rate of cross-over from the chemotherapy to the EGFR TKI (1012). In all of the trials, quality of life parameters were significantly superior with the EGFR TKI (10-12). The summation of information available indicates that EGFR TKIs are the most robust initial therapy for NSCLCs with EGFR exon 19 deletions or L858R.

Gefitinib, erlotinib, and afatinib have approval labels indicating that their use should be restricted to the first-line treatment of NSCLCs harboring the aforementioned classic EGFR mutations. These recommendations are now part of evidence-based practice guidelines for the care of patients with NSCLC $(40,41)$ and have made the EGFR genotype of nonsquamous NSCLC ubiquitous for the day-to-day clinical care of advanced NSCLC (24). The concurrent use of platinum-doublet chemotherapy (carboplatin plus paclitaxel) with erlotinib was not superior to erlotinib alone in the management of never-smokers and light smokers with EGFR mutated tumors (42), and current clinical guidelines only recommend use of EGFR TKI monotherapy in TKInaive patients (41). Gefitinib, erlotinib, and afatinib have not been compared head-to-head in well-designed clinical trials, and it is not known whether one EGFR TKI is superior to the other in terms of anticancer control and tolerability.

The management of NSCLCs that have rarer EGFR TKI-sensitizing mutations is controversial, and most data have been obtained from retrospective series. One useful resource that can be used as a comprehensive catalog of tumor gene-drug response outcomes from individual patients with less common EGFR mutations or compound (i.e., complex or double) mutations is the DNA-mutation Inventory to Refine and Enhance Cancer Treatment (DIRECT) database (43) hosted by Vanderbilt University (http://www.mycancergenome.org/about/direct). NSCLCs with EGFR-G719A (or C, or S), L861Q, exon 19 insertions, and the exon 20 A763 Y764insFQEA respond to gefitinib, erlotinib and afatinib (43). Retrospective cohorts have also confirmed that nonsensitizing EGFR mutations in preclinical models, in specific EGFR exon 20 in-frame insertion mutations (such as V769 D770insASV and D770_N771insSVD), are associated with primary progressive disease to EGFR TKIs (gefitinib, erlotinib, and afatinib) in patients whose NSCLCs harbor these mutations $(21,22,41,44)$.

The use of gefitinib, erlotinib, and afatinib is complicated 
in clinical practice by the dose-dependent and frequent cutaneous, mucosal, and gastrointestinal adverse events associated with EGFR TKIs. At the current recommended starting dose of these agents (250 mg daily of gefitinib, $150 \mathrm{mg}$ daily of erlotinib, and $40 \mathrm{mg}$ daily of afatinib), most patients will have skin toxicities. The rash can be minimal, and managed with topical agents, or severe, requiring dose reductions (10-12). Afatinib is associated with a higher incidence of cutaneous and oral (mucositis) adverse events - which likely reflect the irreversible binding of WT EGFR in noncancerous tissues - than gefitinib or erlotinib (10-12). It is well known that dose reductions of gefitinib and erlotinib can ameliorate symptoms, without affecting efficacy, in most patients with EGFR mutated NSCLC. Indeed, doses as low as $25 \mathrm{mg}$ daily (which is far lower than the label starting dose of $150 \mathrm{mg}$ daily) of erlotinib or $250 \mathrm{mg}$ of gefitinib every other day have been associated with prolonged responses with minimal toxicities $(45,46)$. Preclinical models and clinical trials to determine the most appropriate "biologically effective" dose of EGFR TKIs (if daily dosing, pulsatile doses, or combinations) may in the future change the current paradigm of initial daily dosing of gefitinib, erlotinib, and afatinib (47).

\section{Resistance to EGFR inhibitors in EGFR mutated NSCLC}

The main limitation of the widespread benefits of EGFR TKIs is the development of acquired resistance in patients with EGFR mutated NSCLC treated with this class of drugs. Resistant mutations (i.e., EGFR-T790M) that disrupt kinase-drug binding contacts and activation of shared downstream signaling pathways through other aberrant kinases (i.e., "bypass tracks" or "oncogene kinase co-dependence states") are the predominant models for acquired resistance (Figure 3B) under pressure of a $\mathrm{TKI}$ in preclinical models and clinical samples (48-52). A simple consensus clinical criterion that defines acquired resistance (previous treatment with EGFR TKI, tumor with EGFR sensitizing mutation and systemic progression while on $\mathrm{TKI}$ ) has been loosely used for clinical trial development (53).

The first identified, and most common, mechanism of acquired resistance is the EGFR-T790M mutation located at the gatekeeper amino acid residue $(49,50)$. This genomic event is present in $\sim 60-65 \%$ of cases with acquired resistance to the first-generation (gefitinib and erlotinib) EGFR TKIs and is also present with acquired resistance to second-generation (afatinib) EGFR TKIs $(48,54,55)$. This genomic mutation may be acquired and then selected for during TKI therapy or, more likely, EGFRT790M clones may already exist in the heterogeneous bulk of an EGFR mutated TKI-sensitive NSCLC and then are selected for during TKI therapy $(48,54,55)$. The T790M mutation at the gatekeeper position of the ATP kinase pocket is capable of annulling the sensitization of activating mutations $(16,28)$. EGFR-T790M-bearing NSCLCs with acquired resistance to gefitinib or erlotinib do not respond to the second-generation EGFR TKI afatinib. The latter may be explained by the inability of this irreversible TKI to generate an effective clinical therapeutical window that can deter T790M and not inhibit WT EGFR $(56,57)$. The dual inhibition of EGFR with a monoclonal antibody (cetuximab) and the irreversible TKI afatinib has some activity in NSCLC patients with acquired resistance to EGFR TKIs $(48,56)$. However, this strategy is associated with major cutaneous adverse events (48) that may affect the ability of this scheme to move forward in randomized trials. Covalent pyrimidine inhibitors of EGFR-T790M (i.e., third-generation EGFR TKIs) have been developed (58-60), and these drugs are more potent against EGFR-T790M and less potent against WT EGFR than first- or second-generation EGFR TKIs (58). The compounds in early-stage clinical development are named AZD9291 (55) and CO-1686 (60). Initial results of the phase I clinical trials of these drugs [AZD9291 (AURA series) and CO-1686 (TIGER series)] have already shown responses (RRs that exceed 60\%) in tumors harboring EGFR-T790M $(55,61)$. Registration of phase II and III trials has commenced for both of these compounds, and the Thoracic Oncology community expects that at least one drug will be approved for use in EGFR mutated NSCLC within the next few years.

Bypass signaling tracks as mechanisms of acquired resistance to EGFR TKIs are more varied (Figure 3B). The validated oncogenes that participate in these bypass mechanisms comprise hepatocyte growth factor receptor (MET) $(51,52,62)$, ERBB2 $(63)$, and others $(48,54,55)$. These changes are individually uncommon (with a frequency of less than 15\%), and they can be co-identified with the gatekeeper EGFR-T790M change in the same specimen $(48,54,55)$. Successful treatments for these bypass tracks await clinical trials (55). Some $(<5 \%)$ biopsies of NSCLCs with acquired resistance to firstgeneration EGFR TKIs show histological transformation to poorly differentiated neuroendocrine tumors (52). This proposed transformation to small-cell lung cancer may be mediated in part by activation of pathways that alter the stem cell potential of the TKI-resistant cell $(48,54,55)$.

The selection for and loss of mechanisms of resistance have been noted in patients from whom multiple biopsies were taken during periods on or off an EGFR TKI (52), adding to the involvedness on how to manage resistance.

The current clinical management of patients with acquired resistance to EGFR TKIs remains undetermined owing to the complexity of mechanisms of resistance and the lack of mature trials using EGFR-T790M-specific inhibitors. Therefore, most of the clinical experience in this setting is dictated by retrospective series and extrapolation of preclinical data. In patients not qualified for clinical trials, the algorithm for treatment decisions depends on the sites of symptomatic progression and individual patient characteristics. Multiple groups have reported on 
their experience with "oligometastatic progression" (i.e., oligoprogression), in which the central nervous system (CNS) or other extra-CNS sites may be the main locations of progression (64). In sites such as the brain and bone, local therapy options (surgical or radiotherapy) may allow for continuation of the EGFR TKI as monotherapy for an extended period prior to more widespread systemic progression (64). In many instances of asymptomatic radiographic progression, the continued use of EGFR TKI monotherapy can prevent the flaring of clinically significant disease $(48,54,55)$. The latter may represent uncontrolled growth of TKI-sensitive subclones of the heterogeneous tumor. Eventually, widespread symptomatic progression develops for available EGFR TKIs. Most oncologists have advocated enrollment in clinical trials (that evaluate the aforementioned precision therapies for mechanisms of resistance) or the use of evidence-based cytotoxic chemotherapies (41) for the NSCLC line of therapy in question [i.e., a platinum-doublet for a patient that is chemotherapy naive and single-agent chemotherapy (docetaxel or pemetrexed) for patients who have already received platinum-doublets]. How the use of continued EGFR TKIs in combination with chemotherapy alters clinical outcomes in this population requires wellconducted clinical trials for a robust answer. A retrospective case series matched this strategy to the use of chemotherapy alone and disclosed an improvement in RR but not in other survival parameters (65). Owing to the observed cases of disease flare and the preclinical model that continued inhibition of TKI-sensitive clones is beneficial $(47,48)$, many oncologists continue the tolerated dose of the EGFR TKI in addition to cytotoxic chemotherapies. Clinical trials and evidence-based guidelines for the management of EGFR mutated NSCLCs with acquired resistance to gefitinib, erlotinib, afatinib, and other EGFR TKIs are eagerly awaited.

\section{Ongoing and future research efforts on EGFR mutated NSCLC}

Despite the unprecedented knowledge garnered over the last decade on EGFR mutant biology and on clinical care of EGFR mutated NSCLC with TKIs, many questions remain unanswered. Below we add important questions that should be addressed.

1) What is the role of EGFR TKIs for early stage and locally advanced EGFR mutated NSCLCs? It is possible to speculate that the use of first- and second-generation EGFR TKIs may indeed augment "cure" rates attained with surgery/radiotherapy, or at least significantly delay recurrences when the tumor burden is lower (disease stages I-III). Some retrospective studies have demonstrated discrete improvements in the adjuvant setting use of gefitinib or erlotinib (66). Ongoing prospective and randomized trials are evaluating the role of neoadjuvant or adjuvant gefitinib, erlotinib, and afatinib in the care of patients with stages I-III EGFR mutated NSCLC.

2) What is the most effective biological dosing scheme for EGFR TKIs? Most current EGFR TKIs are used at their maximum tolerated dose in a daily dosing fashion (67). However, innovative preclinical modeling studies have demonstrated that combinations of less-toxic dosing schemes with intermittent pulsatile dosing periods may be a more rational treatment approach (47). Clinical trials using alternative dosing schemes are under way.

3) Which approved EGFR TKI (gefitinib, erlotinib, or afatinib) should be used for NSCLCs with EGFR-L858R or exon 19 deletions, and for NSCLCs with less frequent EGFR mutations (G719X, exon 19 insertions, L861Q, and others)? These are difficult clinical questions that will require significant commitment from clinical trials [some ongoing trials are comparing afatinib (second-generation) to gefitinib/erlotinib (first-generation EGFR TKIs) for NSCLCs with EGFR-L858R or exon 19 deletions] and may eventually hinder not only the efficacy of a given TKI, but also its toxicity profile, cost, and resource implementation by health care system organizations.

4) Should an EGFR TKI be developed for EGFR exon 20 insertion mutants? As described previously, EGFR exon 20 insertion mutants [the third most common class of EGFR mutations (Figure 2B)] are a unique class of activating EGFR mutations that do not have a therapeutic window for use of first-, second-, or third-generation EGFR TKIs compared to WT EGFR $(21,22)$. Therefore, the development of novel classes of EGFR TKIs and/or alternative treatment schedules of available TKIs (that may inhibit EGFR exon 20 insertions and allow for only intermittent exposure of WT EGFR) is an unmet clinical need for EGFR exon 20 insertion mutated NSCLC. Different strategies of care, including use of cytotoxic chemotherapies and biological compounds, are also undergoing clinical trial evaluation for these specific EGFR mutated NSCLCs.

5) What is the role of continuing the original EGFR TKI after radiographic progression on therapy? As detailed above, this question is undergoing detailed clinical trial evaluation, and we should have an answer within the next few years on the benefits of continued EGFR inhibition in the presence of acquired resistance to gefitinib, erlotinib, and afatinib.

6) Which third-generation EGFR TKI is most effective against EGFR-T790M, and what should the Thoracic Oncology community and regulatory agencies tolerate as a registration strategy (RR, PFS, randomized trials against cytotoxic agents)? The clinical development of the covalent pyrimidine inhibitors of EGFR-T790M AZD9291 and CO-1686 - is an important advance for the therapy of acquired resistance to first- and secondgeneration EGFR TKIs mediated by EGFR-T790M (55). The ongoing AURA (for AZD9291) and TIGER (for CO1686) series of phase II and III trials should be able to determine whether these compounds will be approved 
and enter the clinical sphere.

7) What is the role of treatment combinations to delay or prevent acquired resistance to EGFR TKIs in EGFR mutated NSCLC? The true maximization of the clinical benefits of EGFR TKIs for EGFR mutated NSCLC will only occur when therapies can delay or prevent the development of biological mechanisms of resistance (Figure 3B). As more knowledge is acquired on the possible mechanisms of tumor resistance to first-, second-, and third-generation EGFR TKIs and on innovative treatment schedules for kinase inhibitors $(48,54,55)$, the field can foresee the development of clinical strategies that will incorporate multiple inhibitors of EGFR and of bypass signals to provide long-term disease control for these recalcitrant tumors.

\section{Conclusions}

Somatic TKI-sensitizing EGFR mutations are the most robust predictive biomarkers for symptom improvement, radiographic response, and increments in PFS when EGFR TKIs (gefitinib, erlotinib, and afatinib) are used for patients with advanced NSCLC. However, the palliative benefits and increments in survival that EGFR TKIs afford are limited by multiple biological mechanisms of tumor adaptation or resistance. Future efforts toward delaying,

\section{References}

1. Jemal A, Bray F, Center MM, Ferlay J, Ward E, Forman D. Global cancer statistics. CA Cancer J Clin 2011; 61: 69-90, doi: 10.3322/caac.20107.

2. Siegel R, Ma J, Zou Z, Jemal A. Cancer statistics, 2014. CA Cancer J Clin 2014; 64: 9-29, doi: 10.3322/caac.21208.

3. Thorgeirsson TE, Geller F, Sulem P, Rafnar T, Wiste A, Magnusson $\mathrm{KP}$, et al. A variant associated with nicotine dependence, lung cancer and peripheral arterial disease. Nature 2008; 452: 638-642, doi: 10.1038/nature06846.

4. Brennan P, Hainaut P, Boffetta P. Genetics of lung-cancer susceptibility. Lancet Oncol 2011; 12: 399-408, doi: 10.1016/S1470-2045(10)70126-1.

5. Oxnard GR, Nguyen KS, Costa DB. Germline mutations in driver oncogenes and inherited lung cancer risk independent of smoking history. J Natl Cancer Inst 2014; 106: djt361, doi: 10.1093/jnci/djt361.

6. Sun S, Schiller JH, Gazdar AF. Lung cancer in neversmokers - a different disease. Nat Rev Cancer 2007; 7: 778790, doi: 10.1038/nrc2190.

7. Gaughan EM, Cryer SK, Yeap BY, Jackman DM, Costa DB. Family history of lung cancer in never-smokers with nonsmall-cell lung cancer and its association with tumors harboring EGFR mutations. Lung Cancer 2013; 79: 193197, doi: 10.1016/j.lungcan.2012.12.002.

8. Schiller JH, Harrington D, Belani CP, Langer C, Sandler A, Krook J, et al. Comparison of four chemotherapy regimens for advanced non-small-cell lung cancer. $N$ Engl $J$ Med 2002; 346: 92-98, doi: 10.1056/NEJMoa011954.

9. Kwak EL, Bang YJ, Camidge DR, Shaw AT, Solomon B, preventing, and treating resistance hold the promise to boost the median survival of patients with EGFR mutated NSCLC.

\section{Acknowledgments}

The authors would like to thank members of the Kobayashi and Costa laboratories for their insightful comments. Research supported in part by a Career Development Award by the Conquer Cancer Foundation of the American Society of Clinical Oncology (CDA15431), and grants from the American Cancer Society (grant \#RSG 11-186), Lung Cancer Foundation of America - International Association for the Study of Lung Cancer grant, and National Institutes of Health (grants \#CA090578 and \#CA169259).

Presented at the ESPCA Meeting "Sao Paulo Advanced School on Oncogenesis and Translational Medicine for Cancer Treatment", February 17-22, 2014, Ribeirão Preto, SP, Brazil. Meeting sponsored by FAPESP.

D.B. Costa has received consulting fees from Pfizer and Roche. S.S. Kobayashi has received honoraria from Bristol-Myers Squibb. No other conflict of interest is stated.

Maki RG, et al. Anaplastic lymphoma kinase inhibition in non-small-cell lung cancer. N Engl J Med 2010; 363: 16931703, doi: 10.1056/NEJMoa1006448.

10. Mok TS, Wu YL, Thongprasert S, Yang CH, Chu DT, Saijo $\mathrm{N}$, et al. Gefitinib or carboplatin-paclitaxel in pulmonary adenocarcinoma. N Engl J Med 2009; 361: 947-957, doi: 10.1056/NEJMoa0810699.

11. Rosell R, Carcereny E, Gervais R, Vergnenegre A, Massuti B, Felip E, et al. Erlotinib versus standard chemotherapy as first-line treatment for European patients with advanced EGFR mutation-positive non-small-cell lung cancer (EURTAC): a multicentre, open-label, randomised phase 3 trial. Lancet Oncol 2012; 13: 239-246, doi: 10.1016/S14702045(11)70393-X.

12. Sequist LV, Yang JC, Yamamoto N, O'Byrne K, Hirsh V, Mok T, et al. Phase III study of afatinib or cisplatin plus pemetrexed in patients with metastatic lung adenocarcinoma with EGFR mutations. J Clin Oncol 2013; 31: 33273334, doi: 10.1200/JCO.2012.44.2806.

13. Gerber DE, Gandhi L, Costa DB. Management and future directions in non-small cell lung cancer with known activating mutations. Am Soc Clin Oncol Educ Book 2014; e353-e365, doi: 10.14694/EdBook_AM.2014.34.e353.

14. Sharma SV, Bell DW, Settleman J, Haber DA. Epidermal growth factor receptor mutations in lung cancer. Nat Rev Cancer 2007; 7: 169-181, doi: 10.1038/nrc2088.

15. Kumar A, Petri ET, Halmos B, Boggon TJ. Structure and clinical relevance of the epidermal growth factor receptor in human cancer. J Clin Oncol 2008; 26: 1742-1751, doi: 
10.1200/JCO.2007.12.1178

16. Eck MJ, Yun $\mathrm{CH}$. Structural and mechanistic underpinnings of the differential drug sensitivity of EGFR mutations in nonsmall cell lung cancer. Biochim Biophys Acta 2010; 1804: 559-566, doi: 10.1016/j.bbapap.2009.12.010.

17. Lynch TJ, Bell DW, Sordella R, Gurubhagavatula S, Okimoto RA, Brannigan BW, et al. Activating mutations in the epidermal growth factor receptor underlying responsiveness of non-small-cell lung cancer to gefitinib. $N$ Engl $J$ Med 2004; 350: 2129-2139, doi: 10.1056/NEJMoa040938.

18. Paez JG, Janne PA, Lee JC, Tracy S, Greulich H, Gabriel S, et al. EGFR mutations in lung cancer: correlation with clinical response to gefitinib therapy. Science 2004; 304: 1497-1500, doi: 10.1126/science.1099314.

19. Pao W, Miller V, Zakowski M, Doherty J, Politi K, Sarkaria I, et al. EGF receptor gene mutations are common in lung cancers from "never smokers" and are associated with sensitivity of tumors to gefitinib and erlotinib. Proc Natl Acad Sci U S A 2004; 101: 13306-13311, doi: 10.1073/pnas. 0405220101.

20. Shigematsu H, Lin L, Takahashi T, Nomura M, Suzuki M, Wistuba II, et al. Clinical and biological features associated with epidermal growth factor receptor gene mutations in lung cancers. J Natl Cancer Inst 2005; 97: 339-346, doi: 10.1093/jnci/dji055.

21. Yasuda H, Kobayashi S, Costa DB. EGFR exon 20 insertion mutations in non-small-cell lung cancer: preclinical data and clinical implications. Lancet Oncol 2012; 13: e23-e31, doi: 10.1016/S1470-2045(11)70129-2.

22. Yasuda H, Park E, Yun CH, Sng NJ, Lucena-Araujo AR, Yeo WL, et al. Structural, biochemical, and clinical characterization of epidermal growth factor receptor (EGFR) exon 20 insertion mutations in lung cancer. Sci Transl Med 2013; 5: 216ra177, doi: 10.1126/scitranslmed. 3007205.

23. He M, Capelletti M, Nafa K, Yun CH, Arcila ME, Miller VA, et al. EGFR exon 19 insertions: a new family of sensitizing EGFR mutations in lung adenocarcinoma. Clin Cancer Res 2012; 18: 1790-1797, doi: 10.1158/1078-0432.CCR-11-2361.

24. Lindeman NI, Cagle PT, Beasley MB, Chitale DA, Dacic S, Giaccone $\mathrm{G}$, et al. Molecular testing guideline for selection of lung cancer patients for EGFR and ALK tyrosine kinase inhibitors: guideline from the College of American Pathologists, International Association for the Study of Lung Cancer, and Association for Molecular Pathology. J Thorac Oncol 2013; 8: 823-859, doi: 10.1097/JTO. Ob013e318290868f.

25. Oxnard GR, Miller VA, Robson ME, Azzoli CG, Pao W, Ladanyi M, et al. Screening for germline EGFR T790M mutations through lung cancer genotyping. J Thorac Oncol 2012; 7: 1049-1052, doi: 10.1097/JTO.0b013e318250ed9d.

26. Yun $\mathrm{CH}$, Boggon TJ, Li Y, Woo MS, Greulich H, Meyerson $\mathrm{M}$, et al. Structures of lung cancer-derived EGFR mutants and inhibitor complexes: mechanism of activation and insights into differential inhibitor sensitivity. Cancer Cell 2007; 11: 217-227, doi: 10.1016/j.ccr.2006.12.017.

27. Red BM, Yun CH, Lai D, Lemmon MA, Eck MJ, Pao W. Mechanism for activation of mutated epidermal growth factor receptors in lung cancer. Proc Natl Acad Sci U S A 2013; 110: E3595-E3604, doi: 10.1073/pnas.1220050110.

28. Yun $\mathrm{CH}$, Mengwasser KE, Toms AV, Woo MS, Greulich $\mathrm{H}$,
Wong KK, et al. The T790M mutation in EGFR kinase causes drug resistance by increasing the affinity for ATP. Proc Natl Acad Sci U S A 2008; 105: 2070-2075, doi: 10.1073/pnas.0709662105

29. Costa DB, Halmos B, Kumar A, Schumer ST, Huberman MS, Boggon TJ, et al. BIM mediates EGFR tyrosine kinase inhibitor-induced apoptosis in lung cancers with oncogenic EGFR mutations. PLoS Med 2007; 4: 1669-1679, doi: 10. 1371/journal.pmed.0040315.

30. Shepherd FA, Rodrigues PJ, Ciuleanu T, Tan EH, Hirsh V, Thongprasert $\mathrm{S}$, et al. Erlotinib in previously treated nonsmall-cell lung cancer. N Engl J Med 2005; 353: 123-132, doi: $10.1056 /$ NEJMoa050753.

31. Thatcher N, Chang A, Parikh P, Rodrigues PJ, Ciuleanu T, von Pawel J, et al. Gefitinib plus best supportive care in previously treated patients with refractory advanced nonsmall-cell lung cancer: results from a randomised, placebocontrolled, multicentre study (Iressa Survival Evaluation in Lung Cancer). Lancet 2005; 366: 1527-1537, doi: 10.1016/ S0140-6736(05)67625-8.

32. Garassino MC, Martelli O, Broggini M, Farina G, Veronese $\mathrm{S}$, Rulli $\mathrm{E}$, et al. Erlotinib versus docetaxel as second-line treatment of patients with advanced non-small-cell lung cancer and wild-type EGFR tumours (TAILOR): a randomised controlled trial. Lancet Oncol 2013; 14: 981-988, doi: 10.1016/S1470-2045(13)70310-3.

33. Fukuoka M, Wu YL, Thongprasert S, Sunpaweravong P, Leong SS, Sriuranpong V, et al. Biomarker analyses and final overall survival results from a phase III, randomized, open-label, first-line study of gefitinib versus carboplatin/ paclitaxel in clinically selected patients with advanced nonsmall-cell lung cancer in Asia (IPASS). J Clin Oncol 2011; 29: 2866-2874, doi: 10.1200/JCO.2010.33.4235.

34. Nguyen KS, Neal JW. First-line treatment of EGFR-mutant non-small-cell lung cancer: the role of erlotinib and other tyrosine kinase inhibitors. Biologics 2012; 6: 337-345.

35. Han JY, Park K, Kim SW, Lee DH, Kim HY, Kim HT, et al. First-SIGNAL: first-line single-agent iressa versus gemcitabine and cisplatin trial in never-smokers with adenocarcinoma of the lung. J Clin Oncol 2012; 30: 1122-1128, doi: 10.1200/JCO.2011.36.8456.

36. Mitsudomi T, Morita S, Yatabe Y, Negoro S, Okamoto I, Tsurutani J, et al. Gefitinib versus cisplatin plus docetaxel in patients with non-small-cell lung cancer harbouring mutations of the epidermal growth factor receptor (WJTOG3405): an open label, randomised phase 3 trial. Lancet Oncol 2010; 11: 121-128, doi: 10.1016/S1470-2045(09)70364-X.

37. Maemondo M, Inoue A, Kobayashi K, Sugawara S, Oizumi $\mathrm{S}$, Isobe $\mathrm{H}$, et al. Gefitinib or chemotherapy for non-smallcell lung cancer with mutated EGFR. N Engl J Med 2010; 362: 2380-2388, doi: 10.1056/NEJMoa0909530.

38. Zhou C, Wu YL, Chen G, Feng J, Liu XQ, Wang C, et al. Erlotinib versus chemotherapy as first-line treatment for patients with advanced EGFR mutation-positive non-smallcell lung cancer (OPTIMAL, CTONG-0802): a multicentre, open-label, randomised, phase 3 study. Lancet Oncol 2011; 12: 735-742, doi: 10.1016/S1470-2045(11)70184-X.

39. Wu YL, Zhou C, Hu CP, Feng J, Lu S, Huang Y, et al. Afatinib versus cisplatin plus gemcitabine for first-line treatment of Asian patients with advanced non-small-cell lung cancer harbouring EGFR mutations (LUX-Lung 6): an 
open-label, randomised phase 3 trial. Lancet Oncol 2014; 15: 213-222, doi: 10.1016/S1470-2045(13)70604-1.

40. Keedy VL, Temin S, Somerfield MR, Beasley MB, Johnson $\mathrm{DH}$, McShane LM, et al. American Society of Clinical Oncology provisional clinical opinion: epidermal growth factor receptor (EGFR) Mutation testing for patients with advanced non-small-cell lung cancer considering first-line EGFR tyrosine kinase inhibitor therapy. J Clin Oncol 2011; 29: 2121-2127, doi: 10.1200/JCO.2010.31.8923.

41. Ettinger DS, Akerley W, Borghaei $\mathrm{H}$, Chang AC, Cheney RT, Chirieac LR, et al. Non-small cell lung cancer, version 2.2013. J Natl Compr Canc Netw 2013; 11: 645-653.

42. Janne PA, Wang X, Socinski MA, Crawford J, Stinchcombe $\mathrm{TE}, \mathrm{Gu} \mathrm{L}$, et al. Randomized phase II trial of erlotinib alone or with carboplatin and paclitaxel in patients who were never or light former smokers with advanced lung adenocarcinoma: CALGB 30406 trial. J Clin Oncol 2012; 30: 20632069, doi: 10.1200/JCO.2011.40.1315.

43. Yeh P, Chen H, Andrews J, Naser R, Pao W, Horn L. DNAMutation Inventory to Refine and Enhance Cancer Treatment (DIRECT): a catalog of clinically relevant cancer mutations to enable genome-directed anticancer therapy. Clin Cancer Res 2013; 19: 1894-1901, doi: 10.1158/10780432.CCR-12-1894.

44. Yasuda H, de Figueiredo-Pontes LL, Kobayashi S, Costa DB. Preclinical rationale for use of the clinically available multitargeted tyrosine kinase inhibitor crizotinib in ROS1translocated lung cancer. J Thorac Oncol 2012; 7: 10861090, doi: 10.1097/JTO.0b013e3182570919.

45. Satoh H, Inoue A, Kobayashi K, Maemondo M, Oizumi S, Isobe $\mathrm{H}$, et al. Low-dose gefitinib treatment for patients with advanced non-small cell lung cancer harboring sensitive epidermal growth factor receptor mutations. $J$ Thorac Oncol 2011; 6: 1413-1417, doi: 10.1097/JTO.0b013e31821d43a8.

46. Yeo WL, Riely GJ, Yeap BY, Lau MW, Warner JL, Bodio K, et al. Erlotinib at a dose of $25 \mathrm{mg}$ daily for non-small cell lung cancers with EGFR mutations. J Thorac Oncol 2010; 5: 1048-1053.

47. Chmielecki J, Foo J, Oxnard GR, Hutchinson K, Ohashi K, Somwar R, et al. Optimization of dosing for EGFR-mutant non-small cell lung cancer with evolutionary cancer modeling. Sci Transl Med 2011; 3: 90ra59, doi: 10.1126/ scitransImed.3002356.

48. Ohashi K, Maruvka YE, Michor F, Pao W. Epidermal growth factor receptor tyrosine kinase inhibitor-resistant disease. J Clin Oncol 2013; 31: 1070-1080, doi: 10.1200/JCO. 2012.43.3912.

49. Kobayashi S, Boggon TJ, Dayaram T, Janne PA, Kocher O, Meyerson $\mathrm{M}$, et al. EGFR mutation and resistance of nonsmall-cell lung cancer to gefitinib. N Engl J Med 2005; 352: 786-792, doi: 10.1056/NEJMoa044238.

50. Pao W, Miller VA, Politi KA, Riely GJ, Somwar R, Zakowski $M F$, et al. Acquired resistance of lung adenocarcinomas to gefitinib or erlotinib is associated with a second mutation in the EGFR kinase domain. PLoS Med 2005; 2: e73, doi: 10.1371/journal.pmed.0020073.

51. Engelman JA, Zejnullahu K, Mitsudomi T, Song $\mathrm{Y}$, Hyland C, Park JO, et al. MET amplification leads to gefitinib resistance in lung cancer by activating ERBB3 signaling. Science 2007; 316: 1039-1043, doi: 10.1126/science. 1141478.
52. Sequist LV, Waltman BA, Dias-Santagata D, Digumarthy $S$, Turke $A B$, Fidias $P$, et al. Genotypic and histological evolution of lung cancers acquiring resistance to EGFR inhibitors. Sci Transl Med 2011; 3: 75ra26, doi: 10.1126/ scitranslmed.3002003.

53. Jackman D, Pao W, Riely GJ, Engelman JA, Kris MG, Janne PA, et al. Clinical definition of acquired resistance to epidermal growth factor receptor tyrosine kinase inhibitors in non-small-cell lung cancer. J Clin Oncol 2010; 28: 357-360, doi: 10.1200/JCO.2009.24.7049.

54. Gainor JF, Shaw AT. Emerging paradigms in the development of resistance to tyrosine kinase inhibitors in lung cancer. J Clin Oncol 2013; 31: 3987-3996, doi: 10.1200/ JCO.2012.45.2029.

55. Chong CR, Janne PA. The quest to overcome resistance to EGFR-targeted therapies in cancer. Nat Med 2013; 19 1389-1400, doi: 10.1038/nm.3388

56. Regales L, Gong Y, Shen R, de Stanchina E, Vivanco I, Goel A, et al. Dual targeting of EGFR can overcome a major drug resistance mutation in mouse models of EGFR mutant lung cancer. J Clin Invest 2009; 119: 3000-3010.

57. Miller VA, Hirsh V, Cadranel J, Chen YM, Park K, Kim SW, et al. Afatinib versus placebo for patients with advanced, metastatic non-small-cell lung cancer after failure of erlotinib, gefitinib, or both, and one or two lines of chemotherapy (LUX-Lung 1): a phase $2 \mathrm{~b} / 3$ randomised trial. Lancet Oncol 2012; 13: 528-538, doi: 10.1016/S14702045(12)70087-6.

58. Zhou W, Ercan D, Chen L, Yun CH, Li D, Capelletti M, et al. Novel mutant-selective EGFR kinase inhibitors against EGFR T790M. Nature 2009; 462: 1070-1074, doi 10.1038/nature08622.

59. Lee HJ, Schaefer G, Heffron TP, Shao L, Ye X, Sideris S, et al. Noncovalent wild-type-sparing inhibitors of EGFR T790M. Cancer Discov 2013; 3: 168-181, doi: 10.1158/ 2159-8290.CD-12-0357.

60. Walter AO, Sjin RT, Haringsma HJ, Ohashi K, Sun J, Lee K, et al. Discovery of a mutant-selective covalent inhibitor of EGFR that overcomes T790M-mediated resistance in NSCLC. Cancer Discov 2013; 3: 1404-1415, doi: 10.1158/ 2159-8290.CD-13-0314.

61. No authors listed. Targeting resistance in lung cancer Cancer Discov 2013; 3: OF9, doi: 10.1158/2159-8290. CD-ND2013-025.

62. Yu HA, Arcila ME, Rekhtman N, Sima CS, Zakowski MF, Pao W, et al. Analysis of tumor specimens at the time of acquired resistance to EGFR-TKI therapy in 155 patients with EGFR-mutant lung cancers. Clin Cancer Res 2013; 19: 2240-2247, doi: 10.1158/1078-0432.CCR-12-2246.

63. Takezawa K, Pirazzoli V, Arcila ME, Nebhan CA, Song X, de Stanchina E, et al. HER2 amplification: a potential mechanism of acquired resistance to EGFR inhibition in EGFR-mutant lung cancers that lack the second-site EGFRT790M mutation. Cancer Discov 2012; 2: 922-933, doi: 10.1158/2159-8290.CD-12-0108.

64. Weickhardt AJ, Scheier B, Burke JM, Gan G, Lu X, Bunn PA Jr, et al. Local ablative therapy of oligoprogressive disease prolongs disease control by tyrosine kinase inhibitors in oncogene-addicted non-small-cell lung cancer. $J$ Thorac Oncol 2012; 7: 1807-1814, doi: 10.1097/JTO.0b013e3182745948.

65. Goldberg SB, Oxnard GR, Digumarthy S, Muzikansky A, 
Jackman DM, Lennes IT, et al. Chemotherapy with Erlotinib or chemotherapy alone in advanced non-small cell lung cancer with acquired resistance to EGFR tyrosine kinase inhibitors. Oncologist 2013; 18: 1214-1220, doi: 10.1634/ theoncologist.2013-0168.

66. D'Angelo SP, Janjigian YY, Ahye N, Riely GJ, Chaft JE, Sima CS, et al. Distinct clinical course of EGFR-mutant resected lung cancers: results of testing of 1118 surgical specimens and effects of adjuvant gefitinib and erlotinib. J Thorac Oncol 2012; 7: 1815-1822, doi: 10.1097/JTO. Ob013e31826bb7b2.

67. Nguyen KS, Kobayashi S, Costa DB. Acquired resistance to epidermal growth factor receptor tyrosine kinase inhibitors in non-small-cell lung cancers dependent on the epidermal growth factor receptor pathway. Clin Lung Cancer 2009; 10: 281-289. 